\title{
Sudden Death Due to Sarcoma: An Unusual Case and Literature Review
}

\section{Yu-I Li ${ }^{1}, \mathrm{Hsu} \mathrm{WY}^{2}$ and Shun $\mathrm{CT}^{*_{3}}$}

${ }^{1}$ Instructor, Department and Graduate Institute of Forensic Medicine, National Taiwan University, Taipei, Taiwan ${ }^{2}$ Medical Examiner, Taipei District Prosecutors Office, Ministry of Justice, Taiwan

${ }^{3}$ Professor, Department and Graduate Institute of Forensic Medicine, National Taiwan University, Taipei, Taiwan

*Corresponding author: Shun CT, M.D., Ph.D., Department and Graduate Institute of Forensic Medicine, National Taiwan University, No.7, Chung-Shan South Road, Taipei City 100, Taiwan, Fax: 886-2-23218438, Tel: 886-2-23123456 ext 65489, E-mail: ctshun@ntu.edu.tw

Citation: Yu-I Li, Hsu WY, Shun CT (2016) Sudden Death Due to Sarcoma: An Unusual Case and Literature Review. J Forensic Sci Criminol 4(1): 104. doi: 10.15744/2348-9804.4.104

Received Date: January 07, 2016 Accepted Date: February 25, 2016 Published Date: February 26, 2016

\begin{abstract}
Background: Sudden death has varied causes, and autopsy is usually required to determine cause of death. Sarcoma involvement is very infrequent, and detailed pathological evaluation is needed for correct diagnosis. When the medical history of the deceased is unavailable and autopsy is not performed, the true cause of death will not be established. Here we present an unusual case of sarcoma involving heart and lung. We also review 13 cases found in the literature with sarcoma involvement in sudden death.

Results: The current case was a 58-year-old man found dead at home with a history of sarcoma and wide excision. The autopsy showed multiple tumors involving heart and lung. Microscopic findings showed a spindle cell tumor with prominent nuclear pleomorphism. Immunohistochemical studies revealed that the tumor cells were positive for vimentin only. Further analysis, combining the current case with 13 cases from the literature, showed no specific grading or types of sarcoma associated with sudden death. Six of the 14 cases were younger than 1 year old. Ten cases did not have a history of sarcoma prior to death, and 7 of these 10 cases had primary sarcoma sites in vital organs. In the 4 cases with sarcoma history, only 1 case showed a primary site developing in a vital organ. However, the differences in history between these groups were not significant $(p=.145)$.

Conclusion: No types or grading of sarcoma were found to be associated with sudden death. The cases without a prior medical history of sarcoma, compared to the cases with a sarcoma history, seemed to have primary sites in vital organs, but the results were not statistically significant. More studies are needed to clarify the relationship between the history and primary site of sarcoma and sudden death.
\end{abstract}

Keywords: Autopsy; Forensic science; Forensic pathology; Sarcoma; Sudden death; Sudden cardiac death

\section{Introduction}

A natural but unexpected death happening within 1 hour of the onset of final symptoms is called sudden death [1], and almost $85 \%$ of all sudden deaths are of cardiac origin, a leading cause of death in Western countries that is responsible for around 30 to 200 deaths per 100,000 individuals every year [2]. Scene investigation for sudden death requires questioning of the witnesses and family members of the deceased [3]. However, about $40 \%$ of sudden death cases are unwitnessed [4], which makes it more difficult to collect pertinent evidence and information. In such cases, forensic autopsy is usually performed; it is also usually required in order to gain any information. Even with autopsy, however, a small proportion of cases will not reveal a cause of death (COD). In these cases, the COD is categorized as "sudden unexplained death" [5,6].

Soft tissue sarcomas are less common than carcinomas. Sarcomas can occur anywhere in the body; common primary sites are an extremity, the trunk, or the retroperitoneum [7]. The number of newly diagnosed cases of soft tissue sarcoma in the United States in 2004 was 8,680 , accounting for only $0.63 \%$ of all malignant tumors [8]. The rate of sarcoma in all malignancy-related death ranges from $1.5 \%$ to $2 \%[8,9]$.

Sudden death caused by cardiac involvement in malignancy is uncommon, and primary cardiac sarcoma is also rare [10]. Therefore, rates of sarcoma involving the heart causing sudden death are even smaller [11]. The task of establishing a true COD is more difficult when the medical history of sarcoma is not available, or the autopsy is not performed. 
Here we present a case of a 58-year-old man with a history of sarcoma who suffered sudden death, together with a literature review of related cases. The autopsy of the presented case revealed sarcoma involvement in the heart and lung, and immunohistochemical stainings were performed to determine the phenotypes of the sarcoma. The literature research collected 13 additional sudden death cases involving sarcoma.

\section{Materials and Methods}

\section{Chemicals and Antibodies}

Hematoxylin and eosin for histochemical staining were purchased from Leica Biosystems (Singapore). For immunohistochemical staining, the antibodies cytokeratin and CD31 were purchased from BioGenex (Fremont, CA, USA); CD34, vimentin, h-caldesmon, and myogenin were purchased from Dako (Carpinteria, CA, USA); and 3,3'-Diaminobenzidine Quanto was purchased from Thermo Scientific (Waltham, MA, USA).

\section{Immunohistochemical Staining}

Immunohistochemical staining was performed using the Ventana BenchMark autostainer (Tucson, AZ, USA). Antigen

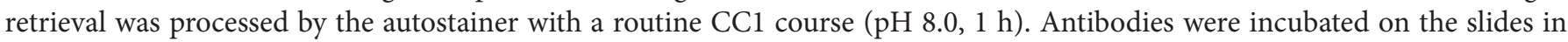
iVIEW-labeled conjugate (Ventana) at $25^{\circ} \mathrm{C}$ for $90 \mathrm{~min}$. The slides were then incubated in a solution of hydrogen peroxide and $3,3^{\prime}$-Diaminobenzidine at $25^{\circ} \mathrm{C}$ for $8 \mathrm{~min}$, and the sections were counterstained with hematoxylin. The slides were reviewed by two pathologists.

\section{Literature Review}

The keywords "sudden death" and "sarcoma" were used for a PubMed search. Cases that were not written in English, did not meet the sudden death definition [1], or did not provide case descriptions were excluded. Thirteen cases were found and included for analysis.

\section{Statistical Analysis}

Fisher's exact test and other statistical calculations, including means and standard deviations, were performed using SPSS 16.0 (IBM, New York, NY, U.S.A.)

\section{Results}

\section{Case Presentation}

A 58-year-old man living alone with no systemic diseases was found dead face down in his kitchen. His family stated that he had no discomfort in recent days. Four years before his death, he had a wound over his left ankle that did not heal spontaneously. Later, he noticed a protruding mass on the left ankle, but he had not sought medical assistance until 9 months before he died. He then received wide excision, and a pathology report showed high-grade sarcoma. He did not receive regular follow-up or any adjuvant therapy after excision, however. Five months before his death, he noted persistent bleeding over his left lower leg. Local recurrence of sarcoma was suspected and above-knee amputation was performed.

An autopsy was executed to investigate the COD. Height and body weight were 172 centimeters and 70 kilograms. No brain hemorrhage or external traumatic lesions were noted. The weights of the heart and right and left lungs were 590, 750, and 900 grams respectively. Tumor masses were noted in the right ventricle (Figure 1a) and lung (Figure 1b). The outflow of the right ventricle was completely blocked by the tumor mass. The cut surface of the mass was soft, and areas of necrosis were seen. Other organs were not remarkable. The toxicological panels did not indicate use of recreational drugs or poisoning. The blood alcohol level was below the limit of detection. Microscopic findings revealed a spindle cell tumor arranged in a sheet-like pattern. Nuclear pleomorphism was conspicuous (Figure 2). An immunohistochemical study showed positivity for vimentin in the spindle cells (Figure 3a), while other markers, including CD31, CD34, cytokeratin, h-caldesmon, and myogenin, were negative (Figures 3b-f). The COD was sudden death caused by high-grade sarcoma blocking the outflow of the right ventricle.

\section{Literature Review}

Thirteen cases of sudden death involving sarcoma were found in the literature. These cases and the presented case are summarized in Table 1 . The mean age at death was 30 years $(30 \pm 8.3)$, although seven cases happened before adulthood. Of the seven juvenile cases, four were younger than 1 year old, two were between 1 and 6 years old, and one (case 12) was 19 years old. The six adult cases and the presented case (case 14) were all more than 35 years old at time of death.

Regarding medical history, 10 of the 14 cases did not have a history of sarcoma prior to death. The other 4 cases, on the contrary, were diagnosed with sarcoma prior to the sudden death. In the 10 cases without previous sarcoma history, 7 showed primary sarcoma sites in vital organs, including heart, lung, or brain. In the 4 cases with sarcoma history, only 1 case showed a primary site of sarcoma developing in a vital organ. However, the differences in history between these groups were not statistically significant $(p=.145)$. 


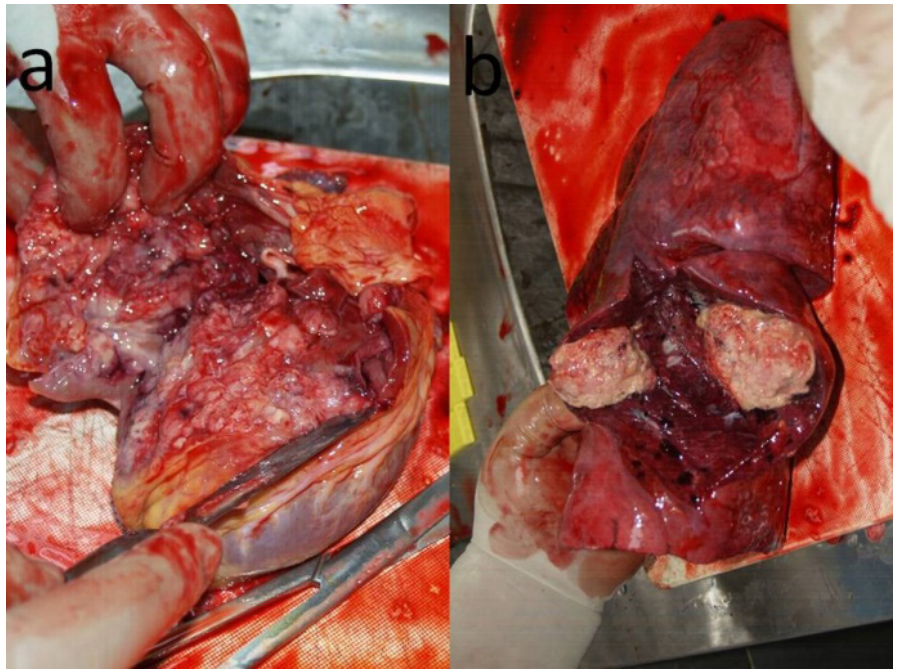

Figure 1: Macroscopic pictures of tumors in the heart and lung. (a) A grayish-white tumor resided in the right ventricle with infiltration in the myocardium. (b) One of the tumors was located in the right middle lobe of the lung

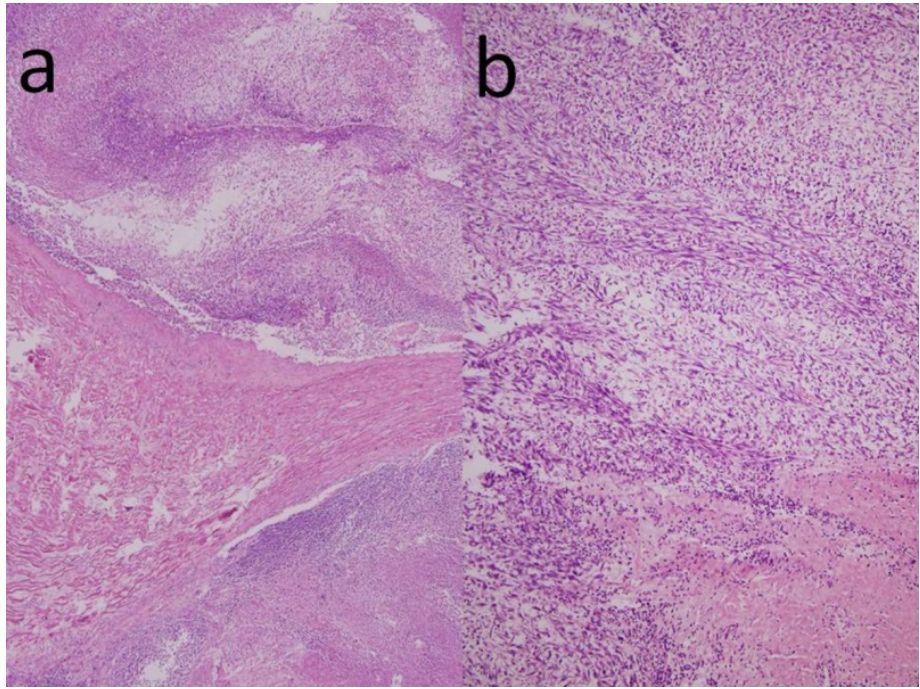

Figure 2: Microscopic pictures of tumors in the heart and lung (a) Spindle cells with prominent necrosis infiltrates in the myocardium, magnification rate: 40X (b) Prominent nuclear atypia, magnification rate: 100X
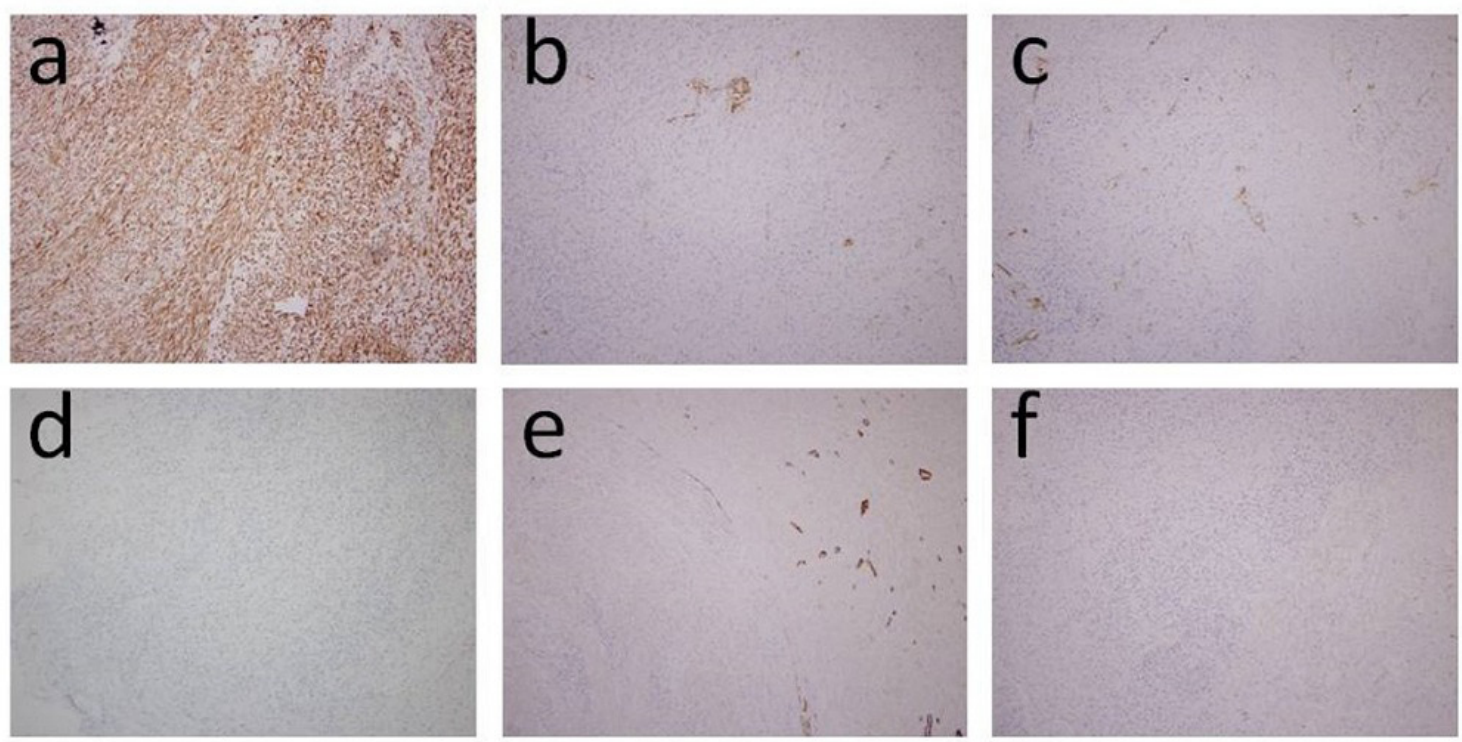

Figure 3: Immmunohistochemical studies of the sarcoma (a) Vimentin (b) CD31 (c) CD34 (d) Cytokeratin (e) H-caldesmon (f) Myogenin 
All cases demonstrated either heart or lung involvement of sarcoma except for case 13, whose primary and only sarcoma involvement was in the brain. Nine out of 14 cases showed cardiac involvement of sarcoma, and 4 out of 14 cases showed lung involvement. The presented case is the only case who manifested both cardiac and lung involvement.

The final diagnoses and grading of sarcoma in these cases were varied. The results suggested that differences in type or grade do not play an important role in sudden death. In diagnosing the types of sarcoma, cases 9 through 13 did not use any immunohistochemical staining. The cases reported after 1994, including our case, all used immunohistochemical panels to achieve the final diagnoses.

\section{Discussion}

Cases of sudden death usually require autopsy to determine COD [5]. However, less than 50\% of sudden death cases actually receive autopsy [15]. Among those that do receive autopsy, findings of sarcoma have been reported [12-14] but are very unusual. Moreover, our results show that in most cases of sarcoma causing sudden death, the deceased did not have a medical history of sarcoma, meaning that scene investigation and questioning of family members alone may not provide sufficient information to determine COD. Therefore, promoting an increased rate of autopsy is necessary to establish a correct COD in these cases.

Six out of 14 cases reviewed in our study were younger than 6 years old at time of death. Trutmann and colleagues found that incidence rates of soft-tissue sarcoma peak in two age groups, 10 to 19 years and 70 to 79 years [16], yet both of these age groups are much older than the cases reviewed here. It may be that younger cases with sarcoma, especially children less than 1 year old, have less-favorable survival rates [17]. The idea that these infants or children with sarcoma, therefore, may present as sudden death, is supported by the fact that almost half of the sarcoma-induced sudden deaths reviewed in this study were quite young. These findings may also contribute to future studies in sudden infant death that include malignancy, especially sarcoma, in the differential diagnoses and etiologies [18].

Seven of the 10 cases without medical history of sarcoma had vital organs, including heart, lung, and brain, as the primary site of sarcoma, whereas only 1 of the 4 cases with a history (case 12) had vital organs as primary site. However, the differences between the groups were not statistically significant, most likely due to the small number of cases ( $p=.145$ in the results, but $p=.006$ by duplicating the cases).

The possible correlation between medical history and vital organs as primary sites may be explained by the fact that cases with primary sites of sarcoma in vital organs are more vulnerable to sudden death, and thus are less likely to be diagnosed before death. Sudden death caused by carcinoma among people without a medical history has been reported, and these were initially presented with vital organ involvement as well [19-21]. Future studies are needed to clarify the correlation between medical history and primary sites of sarcoma.

Five cases in this review, all published before 1994, solely relied on traditional hematoxylin-eosin staining and did not perform immunohistochemical staining to achieve the final diagnoses [22-26]. The other nine cases reviewed here all used immunohistochemical methods to make diagnoses. The adaptation of immunologic methods to histochemical techniques has revolutionized diagnostic pathology, especially for soft-tissue malignancy [27]. Newer immunohistochemical markers facilitate the progress of defining the tumor cell lineage and origin much more accurately than the traditional hematoxylin-eosin method [28-30]. Moreover, molecular diagnostic tools, such as fluorescence in situ hybridization (FISH) and DNA sequencing, are now prevalent in diagnosing sarcoma [31,32]. Using these molecular tools to determine COD is now accepted and can be expected in future studies [33].

\begin{tabular}{|c|c|c|c|c|c|c|c|c|c|}
\hline Case & $\begin{array}{c}\text { Age } \\
\text { (years) }\end{array}$ & Gender & $\begin{array}{l}\text { Known } \\
\text { History }\end{array}$ & $\begin{array}{c}\text { Heart } \\
\text { Involvement }\end{array}$ & $\begin{array}{c}\text { Lung } \\
\text { Involvement }\end{array}$ & Diagnosis & Primary Site & $\mathrm{IHC}^{*}$ & Ref. \\
\hline 1 & 67 & Male & - & + & - & Liposarcoma & Heart & + & [34] \\
\hline 2 & $<1$ & Female & - & + & - & Sarcoma, low grade & Heart & + & [35] \\
\hline 3 & 42 & Female & - & + & - & Intimal sarcoma & Heart & + & [36] \\
\hline 4 & 77 & Female & + & + & - & $\begin{array}{c}\text { Sarcoma, } \\
\text { undifferentiated }\end{array}$ & Urinary bladder & + & [37] \\
\hline 5 & 5 & Female & - & + & - & $\begin{array}{c}\text { Myofibroblastic } \\
\text { sarcoma, low grade }\end{array}$ & Heart & + & [38] \\
\hline 6 & $<1$ & Female & - & - & + & $\begin{array}{c}\text { Malignant } \\
\text { hemangioendothelioma }\end{array}$ & $\begin{array}{l}\text { Thoracic } \\
\text { cavity** }\end{array}$ & + & [39] \\
\hline 7 & 36 & Female & + & - & + & $\begin{array}{c}\text { Malignant } \\
\text { mesenchymoma }\end{array}$ & Retroperitoneum ${ }^{\star *}$ & + & [40] \\
\hline 8 & $<1$ & Male & - & - & - & $\begin{array}{c}\text { Embryonal } \\
\text { rhabdomyosarcoma }\end{array}$ & Prostate & + & [41] \\
\hline 9 & 75 & Male & - & + & - & $\begin{array}{c}\text { Sarcoma, } \\
\text { undifferentiated }\end{array}$ & Heart & - & [26] \\
\hline
\end{tabular}




\begin{tabular}{|c|c|c|c|c|c|c|c|c|c|}
\hline Case & $\begin{array}{c}\text { Age } \\
\text { (years) }\end{array}$ & Gender & $\begin{array}{c}\text { Known } \\
\text { History }\end{array}$ & $\begin{array}{c}\text { Heart } \\
\text { Involvement }\end{array}$ & $\begin{array}{c}\text { Lung } \\
\text { Involvement }\end{array}$ & Diagnosis & Primary Site & IHC $^{*}$ & Ref. \\
\hline 10 & $<1$ & Male & - & - & + & Pulmonary blastoma & Lung & - & {$[25]$} \\
\hline 11 & 2 & Female & + & + & - & Myxosarcoma & Heart & - & {$[24]$} \\
\hline 12 & 19 & Male & - & + & - & Chondrosarcoma & Pelvis & - & {$[23]$} \\
\hline 13 & 39 & Female & - & - & - & Fibrosarcoma & Brain & - & {$[22]$} \\
\hline 14 & 58 & Male & + & + & + & Sarcoma, high grade & Leg & + & $* * *$ \\
\hline
\end{tabular}

* Immunohistochemical staining

** The primary site was the soft tissue in the body cavity

$* * *$ The current presented case

Table 1: Summary of 14 Cases of Sarcoma Involvement in Sudden Death

\section{Conclusion}

Here we have presented an unusual case of sarcoma causing sudden death. We reviewed 13 cases in the literature. The results showed that no specific type of sarcoma diagnosis occurred more frequently in these cases, neither did the grading of sarcoma have a significant effect. It seemed that in the cases without a medical history of sarcoma prior to the sudden death, the origin of the sarcoma may be more likely to reside in vital organs, but again, the result was not statistically significant. More studies and an increase in the rate of autopsy will help shed light on the relationship between the history and primary site of sarcoma in the sudden death cases.

\section{References}

1. de la Grandmaison GL, Durigon M (2002) Sudden adult death: a medico-legal series of 77 cases between 1995 and 2000. Med Sci Law 42: $225-32$.

2. Pachon M, Almendral J (2011) Sudden death: managing the patient who survives. Heart 97: 1619-25.

3. de la Grandmaison GL (2006) Is there progress in the autopsy diagnosis of sudden unexpected death in adults? Forensic Sci Int156: 138-44.

4. de Vreede-Swagemakers JJ, Gorgels AP, Dubois-Arbouw WI, van Ree JW, Daemen MJ, et al. (1997) Out-of-hospital cardiac arrest in the 1990's: a populationbased study in the Maastricht area on incidence, characteristics and survival. J Am Coll Cardiol 30: 1500-5.

5. Campuzano O, Allegue C, Partemi S, Iglesias A, Oliva A, et al. (2014) Negative autopsy and sudden cardiac death. Int J Legal Med $128: 599-606$.

6. Milroy CM (2007) The autopsy in cases of unascertained sudden death. Curr Diagn Pathol 13: 401-9.

7. Cormier JN, Pollock RE (2004) Soft Tissue Sarcomas. CA Cancer J Clin 54: 94-109.

8. Jemal A, Tiwari RC, Murray T, Ghafoor A, Samuels A, et al. (2004) Cancer Statistics, 2004. CA Cancer J Clin 54: 8-29.

9. Ferrari A, Sultan I, Huang TT, Rodriguez-Galindo C, Shehadeh A, et al. (2011) Soft tissue sarcoma across the age spectrum: a population-based study from the Surveillance Epidemiology and End Results database. Pediatr Blood Cancer 57: 943-9.

10. Shanmugam G (2006) Primary cardiac sarcoma. Eur J Cardio-thoracic Surg 29: 925-32.

11. Langlois NE (2009) Sudden adult death. Forensic Sci Med Pathol 5: 210-32.

12. Guo Y, Xie D, Yan J, Cai J, Yin G, et al. (2013) Primary pulmonary rhabdomyosarcoma with brain metastases in a child: a case report with medico-legal implications. J Forensic Legal Med 20: 720-3.

13. Nakaya T, Morita K, Kurata A, Ushiku T, Igarashi T, et al. (2014) Multifocal kaposiform hemangioendothelioma in multiple visceral organs: an autopsy of 9-day-old female baby. Human pathol 45: 1773-7.

14. Podduturi V, Guileyardo JM, Soto LR, Krause JR (2015) A case series of clinically undiagnosed hematopoietic neoplasms discovered at autopsy. Am J Clin Pathol 143: 854-60.

15. Hofer F, Fellmann F, Schläpfer J, Michaud K (2014) Sudden cardiac death in the young (5-39 years) in the canton of Vaud, Switzerland. BMC cardiovascular disorders 14: 140 .

16. Trautmann F, Schuler M, Schmitt J (2015) Burden of soft-tissue and bone sarcoma in routine care: Estimation of incidence, prevalence and survival for health services research. Cancer Epidemiol 39: 440-6.

17. Pastore G, Peris-Bonet R, Carli M, Martínez-García C, Sánchez de Toledo J, et al. (2006) Childhood soft tissue sarcomas incidence and survival in European children (1978-1997): report from the Automated Childhood Cancer Information System project. Eur J Cancer 42: 2136-49.

18. Wong LC, Behr ER (2014) Sudden unexplained death in infants and children: the role of undiagnosed inherited cardiac conditions. Europace 16: $1706-13$.

19. Miura H, Kitamura S, Yamada H (2008) An autopsy case of autoimmune pancreatitis after a 6-year history of steroid therapy accompanied by malignant dissemination of unknown origin. Eur J Gastroenterol Hepatol 20: 930-4.

20. Laohachewin D, André F, Tschaharganeh D, Katus HA, Korosoglou G, et al. (2014) Sudden unexpected death in a patient with tumour associated pulmonary embolism. Case Rep Med 2014: 396832.

21. Dean SA, Mathis B, Litzky LA, Hood IC (2015) Sudden Death by Occult Metastatic Carcinoma. J Forensic Sciences doi: 10.1111/1556-4029.12837.

22. Greendyke RM (1965) Primary Fibrosarcoma of Brain with Ossification: Report of A Case. Arch Pathol 80: 225-7.

23. Borzotta AP, Riddick L, Sadlack W, Chun B (1978) Sudden death from massive tumor embolization of chondrosarcoma. Report of a case. J Bone Joint Surg Am 60: 561-3. 
24. Mahar LJ, Lie JT, Groover RV, Sweard JB, Puga FJ, et al. (1979) Primary cardiac myxosarcoma in a child. Mayo Clin Proc 54: 261-6.

25. Ashworth TG (1983) Pulmonary blastoma, a true congenital neoplasm. Histopathology 7: 585-94.

26. Varriale P, Chryssos B (1991) Pulmonary artery sarcoma: another cause of sudden death. Clin Cardiol 14: 160-4.

27. Angervall L, Kindblom LG (1993) Principles for pathologic-anatomic diagnosis and classification of soft-tissue sarcomas. Clin Orthop Relat Res 9-18.

28. Ordonez NG (1998) Application of immunocytochemistry in the diagnosis of soft tissue sarcomas: a review and update. Adv Anat Pathol 5: 67-85.

29. Brooks JS, Lee S (2015) Contemporary diagnostics: sarcoma pathology update. J Surg Oncol 111: 513-9.

30. Lin G, Doyle LA (2015) An update on the application of newly described immunohistochemical markers in soft tissue pathology. Arch Pathol Lab Med 139: 106-21.

31. Lazar A, Abruzzo LV, Pollock RE, Lee S, Czerniak B (2006) Molecular diagnosis of sarcomas: chromosomal translocations in sarcomas. Arch Pathol Lab Med 130: 1199-207.

32. Hameed M (2014) Molecular diagnosis of soft tissue neoplasia: clinical applications and recent advances. Expert Rev Mol Diagn 14: $961-77$.

33. Thiene G (2014) Sudden cardiac death and cardiovascular pathology: from anatomic theater to double helix. Am J Cardiol 114: 1930-6.

34. Papavdi A, Agapitos E (2013) Undiagnosed primary cardiac liposarcoma in an adult: a case report and review of the literature. Am J Forensic Med Pathol 34: 299-301.

35. Cascini F, Longo F, Parenti D, Capelli A (2012) A case of sudden infant death due to a primary cardiac sarcoma. J Forensic Sci 57: 1368-71.

36. Jiang WX, Gao CR, Sun JH, Bunai Y (2009) Sudden cardiac death caused by a primary intimal sarcoma of the left coronary artery. Int J Legal Med 123: 503-6.

37. Mirza SB, Puttasidiah P, Panesar SS, Jane AF, David RJ, et al. (2008) Sarcoma of the bladder with metastasis to the left ventricle. Can Urol Assoc J 2: 143-4.

38. Eisenstat J, Gilson T, Reimann J, Sampson B (2008) Low-grade myofibroblastic sarcoma of the heart causing sudden death. Cardiovasc Pathol 17: 55-9.

39. Perrot LJ (1997) Malignant hemangioendothelioma: a case of sudden unexpected death in infancy. Am J Forensic Med Pathol 18: $96-9$.

40. Rees H, Ang LC (1996) Massive pulmonary tumor emboli in a sarcoma. An unusual cause of sudden death. Am J Forensic Med Pathol 17: 146-50.

41. Ruszkiewicz A, Vernon-Roberts E (1994) Incidental embryonal rhabdomyosarcoma of the prostate gland in sudden infant death syndrome. Am J Forensic Med Pathol 15: 79-81

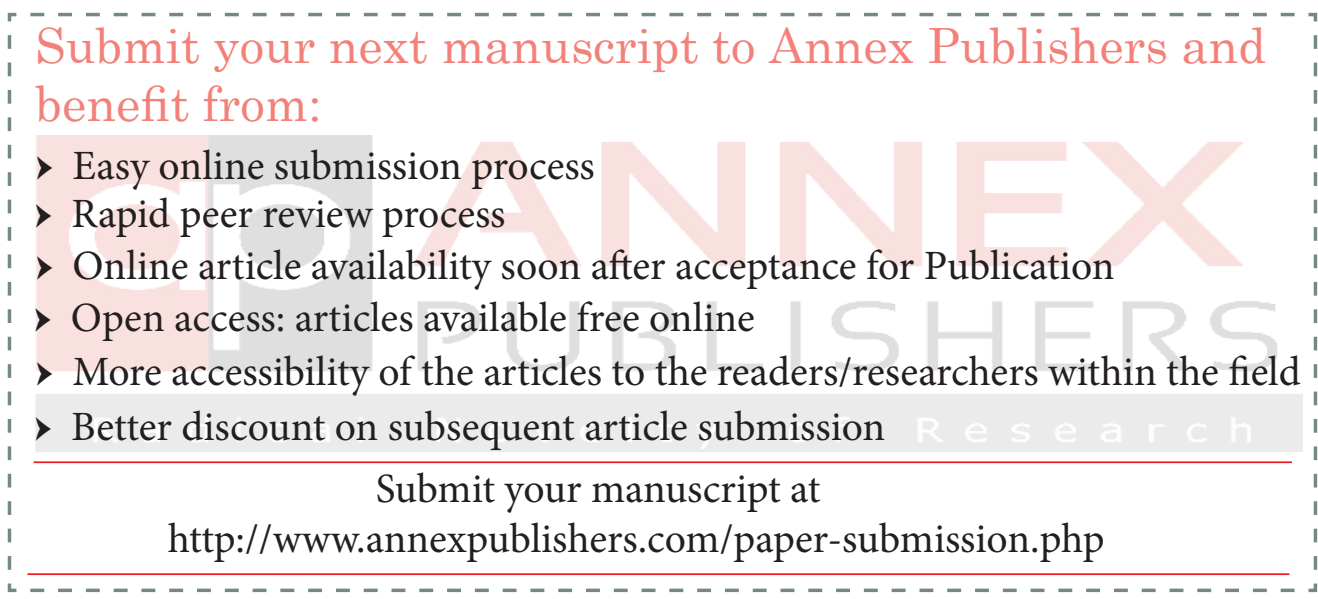

